\title{
Pathophysiological Mechanism of Intestinal Gas Production
}

\author{
Akefe I 0* \\ Department of Physiology, Ahmadu Bello University, Zaria, Nigeria
}

Received: December 08, 2017; Published: December 19, 2017

*Corresponding author: Akefe I O, Department of Physiology, Faculty of Veterinary Medicine, Ahmadu Bello University, Zaria, Nigeria

\begin{abstract}
The production and accumulation of gases in the intestine has been reported more frequently in recent times. Accumulation of gas in the intestine without proper remediation has been associated with several pathologic morbidities and consequently mortality in unattended cases. Intestinal gases are primarily produced by oral ingestion of air, activities of the inhabitant bacteria organisms, and in some cases, other gastrointestinal diseases associated with gas production. The most important intestinal gases identified and isolated within the gut lumen have been reported to include; nitrogen, hydrogen, methane, oxygen and carbon di oxide. Intestinal gas accumulation and subsequent explosions has been implicated as the culprit in several colonic surgical complications. The hyper production of Hydrogen in response to certain sugars like lactose may be considered the expression of intolerance or a sugar mal digestion, with an abnormal fermentation by gut microbiota. An enhanced understanding of the pathophysiological intricacies involved in the production of intestinal gases is essential for the advancement of present strategies utilized in the remediation of diseases associated with intestinal gas production and accumulation.
\end{abstract}

Keywords: Gas; Intestinal; Hydrogen; Methane; Carbon di oxide; Oxygen; Pathophysiology

Abbreviations: SRB: Sulphate Reducing Bacteria; IBS: Irritable Bowel Syndrome; MTT: Mean Transit Time

\section{Introduction}

The presence of hydrogen and methane in intestinal lumen was first suggested in 1816, when Magendie hypothesized that these gases were present in the intestine of guillotined convicts [1]. Eventually, reports of explosions during colonic surgery supported the notion that the gut may contain combustibles gas [2]. Colonic gas explosion, although rare, is one of the most alarming iatrogenic complications during colonoscopy with electrocautery [3]. The explosion results from the accumulation of colonic gases at explosive concentrations and may be averted by scrupulous bowel preparation prior to the surgery [2].

\section{Sources of Intestinal Gas Production}

Aerophagia: Frequently swallowing large amounts of air (aerophagia) may lead to continuous and repeated belching. Air swallowing is the major source of gas in the intestine and stomach. It is conventional to swallow a small amount of air when eating and drinking and when swallowing saliva. Vast amounts of air may be swallowed when rapidly eating foods, gulping liquids, chewing gum, and during smoking [1].

Bacterial Production of Intestinal Gases: The colon provides habitation for billions of harmless bacteria, some of which support bowel health. Carbohydrates are normally digested by enzymes in the small intestine. However, certain carbohydrates are incompletely digested, allowing bacteria in the colon to digest them.
The byproducts of bacterial digestion included or less vapors, such as carbon dioxide, hydrogen, and methane [4]. Minor components of flatus (gas expelled through the anus) have an unpleasant odor, including trace amounts of sulfur containing gases that are liberated by bacteria in the large intestine. Some carbohydrates, such as raffinose, are improperly digested, and therefore cause increased amounts of gas. Vegetables containing raffinose, such as cabbage, Brussels sprouts, asparagus, broccoli, and some whole grains tend to cause more gas and flatulence [5]. Some people are unable to digest certain carbohydrates. A classic example is lactose, the major sugar contained in dairy products. Thus, consuming large amounts of lactose may lead to increased gas production, alongside cramping and consequently diarrhea [1].

\section{Diseases Associated With Increased Intestinal Gas Production}

Certain diseases also result in excessive bloating and intestinal gas formation. For instance, people with diabetes or scleroderma may, over time, have slowing in the peristaltic activity of the small intestine. This may lead to bacterial overgrowth within the bowel, with poor digestion of sugars and other nutrients [6]. Carbohydrate mal absorption can occur in people with celiac disease (intolerance to a protein), short bowel syndrome, and those who have rare primary disorders of the enzymes needed to digest specific forms of carbohydrates [7]. 


\section{Characterization of Intestinal Gases}

Among the first complete reports characterizing intestinal gases contents include the important work of Levitt and Kirk. They identified five major components of intestinal gases and estimated their concentrations [6].
i. $\quad$ Nitrogen $-\mathrm{N}_{2}$ (23 to $80 \%$ )
ii. Oxygen $-\mathrm{O}_{2}$ ( 0.1 to $\left.2.3 \%\right)$
iii. Hydrogen $-\mathrm{H}_{2}$ (0.06 to 47\%)
iv. Methane $-\mathrm{CH}_{4}(0$ to $26 \%)$
v. Carbon dioxide $-\mathrm{CO}_{2}$ (5.1 to $29 \%$ )

Hydrogen and methane are the two major combustible gases contending the normal colon [8]. They are produced in the colonic lumen from fermentation of non absorbable (lactulose, mannitol) or incompletely absorbed (lactose, fructose, sorbitol) carbohydrates by the colonic flora, from air swallowing (absence of the gastric bubble in subjects with advanced achalasia), from $\mathrm{CO}_{2}$ produced by interaction of bicarbonate and acid in duodenum, and from diffusivity of a gas across the mucosa of the gastro intestinal tract $\left(\mathrm{CO}_{2}\right.$ diffuses much more rapidly than $\mathrm{H}_{2}, \mathrm{CH}_{4}, \mathrm{~N}_{2}$, and $\mathrm{O}_{2}$ ) [9]. Since 1974 it has been known that no mammalian cell is capable of producing $\mathrm{H}_{2}$ or $\mathrm{CH}_{4}$, but bacteria do it by fermentation of appropriate substrates under anaerobic conditions1.

In these light 64 strains of intestinal bacteria were cultured under anaerobic conditions in lactulose containing media to assess their ability to ferment lactulose. Some organisms were unable to metabolize disaccharide, while others; example is clostridia and lactobacilli, extensively metabolized lactulose. Intestinal gases, however, are not the only metabolites originating from bacterial fermentations of indigestible carbohydrates. Qualitative analyses of the fermentation products in vitro indicated that the major nongaseous metabolites were acetic, lactic and butyric acids that are characteristically produced by clostridia. Bacteroides predominantly metabolized lactulose to acetic and succinic acids, but produced smaller quantities of higher fatty acids during lactulose fermentation than with basal medium alone. Hydrogen and carbon dioxide were the only gases detected [10]. Starting from these settings, it is easy to understand that hydrogen and methane are just two components of the complex activity of the metabolic gut microbiota activity involving "indigestible" carbohydrates which are part of the human diet [6].

\section{Pathophysiological Mechanism of Intestinal Gas Production}

Hydrogen Gas: In 1974, Newman et al. [1] found that after feeding baked beans to volunteers, $\mathrm{H}_{2}$ appeared in exhaled breath and that the rise in breath $\mathrm{H}_{2}$ concentration paralleled the subjects' abdominal discomfort. In vitro studies further demonstrated that fecal or ileal flora, incubated with various substrates produced striking amounts of $\mathrm{CO}_{2}$ and $\mathrm{H}_{2}$. When stacchyose, a sugar abundantly present in baked beans, was incubated with ileal or colonic flora as much $\mathrm{CO}_{2}$ or $\mathrm{H}_{2}$ were evolved as when glucose, galactose, or other common sugars were incubated. This was of particular interest since stacchyose is an oligosaccharide hydrolyzed by an enzyme not present in human intestine but possessed by enteric bacteria that are able to split stacchyose into fermentable monosaccharides [1]. It is likely that the wind producing potential of a food is related to its content of non absorbable fermentable substrates, most probably oligosaccharides and fibrous in nature. As far as concern the diet, it is common folklore, verified by old studies, that apple, grape and prune juices, all Bran cereals more than refined wheat or bland formula diets, soya beans, lima beans are all gas inducer food; in contrast orange, apricot, pineapples and peanuts are poor gases inducers in humans [5].

Studies from same period showed that a minority of people would display an excessive production of gas because of carbohydrate mal absorption (lactose mal absorption or celiac disease) [9]: these studies brought over time the definition of carbohydrates mala absorption. Both Levitt and Calloway, in fact, reported an excellent correlation between lactose tolerance tests and breath $\mathrm{H}_{2}$ measurements after lactose ingestion. Levitt has shown that as little as $5 \mathrm{~g}$ of lactose was followed by a rise in breath $\mathrm{H}_{2}$ in severely hypolactasic subjects, while Calloway has established that a rise in breath $\mathrm{H}_{2}$ greater than $20 \mathrm{ppm}$ after ingestion of $0.5 \mathrm{~g}$ lactose/ $\mathrm{kg}$ was as accurate as a lactose tolerance test in diagnosing lactose mal absorption. In addition the amount of lactose absorbed was dose dependent and there was no detectable $\mathrm{H}_{2}$ in breath in some lactase deficient subjects when the test dose was halved, though, as showed by Levitt, some subjects were exquisitely intolerant to the sugar [10].

Methane $\left(\mathbf{C H}_{4}\right)$ Gas: The world's population may be classified into $\mathrm{CH}_{4}$ 'producers' and $\mathrm{CH}_{4}$ 'non producers', with some familial tendency towards $\mathrm{CH}_{4}$ production, but with no evidence that spouses share the propensity. Producers of $\mathrm{CH}_{4}$ usually exhale a concentration of more than $23 \mathrm{ppm}$ while 'non producers' exhale less than 3 or $4 \mathrm{ppm} . \mathrm{CH}_{4}$ production never begins before the age of 2 [10]. It was observed that the pattern of $\mathrm{CH}_{4}$ exhalation is fairly constant in $\mathrm{CH}_{4}$ producers over the course of a 24 hour day, thus apparently not depending on an exogenous substrate: in fact it was hypothesized and then demonstrated that $\mathrm{CH}_{4}$ is generated under strictly anaerobic conditions as the result of the reduction of $\mathrm{CO}_{2}$ with $\mathrm{H}_{2}$, arising from the fermentative action of bacteria1. The main $\mathrm{CH}_{4}$ producing organism in humans is Methanobrevibactersmithii, but other microorganisms in the human gut, such as certain Clostridium and Bacteroides species, are capable of producing $\mathrm{CH}_{4}$ [4]. It is estimated that the conversion of hydrogen in methane is a reaction associated to a clear reduction of intestinal gas volume: in fact 4 moles of hydrogen and 1 of $\mathrm{CO}_{2}$ are metabolized in order to produce 1 mole of methane and 2 of water. In addition, if $\mathrm{H}_{2}$ is not metabolized, the volume of gas accumulating in the gut will be substantially greater than if $\mathrm{CH}_{4}$ is produced [11].

\section{Catabolic Pathways of Hydrogen in the Gut}

Hydrogen could be metabolized not just in methane by gut bacteria but also through a variety of other pathways, including sulphate reduction and acetogenesis [11]. An interesting paper assessed in vitro factors associated to a different catabolic activity. In this paper, stools were taken from 30 healthy subjects and 
incubated as 5\% (w/v) slurries with Lintner's starch. On the basis of methanogenesis rates and numbers of sulphate reducing bacteria (SRB) in faces, the subjects were divided into two groups; A that had less than $107 \mathrm{SRB} / g$ dry weight faeces and $B$ that had more than $107 \mathrm{SRB} / \mathrm{g}$ of faces. Most subjects (group $\mathrm{A} ; \mathrm{n}=23$ ) shared high rates of fecal methanogenesis. In this group, 21 out of 23 subjects had methane in the breath. None of the subjects in group B $(n=7)$ had methane in the breath and produced methane in vitro, while had high rates of sulphate reduction in feces and higher concentrations of sulphide. Considerable methane production occurred only when sulphate reducing bacteria were not active [9].

The SRB were found using lactate as a source of carbon and energy and their counts showed a strongly positive association with $\mathrm{H}_{2} \mathrm{~S}$ concentrations in faces. So sulphate reduction and methanogenesis seems to be mutually exclusive in the colon and this is probably linked to sulphate availability [12]. When sulphate is available, SRB are known to have higher substrate affinity for hydrogen and $\mathrm{H}_{2} \mathrm{~S}$ is produced. In conditions of low sulphate availability methanogenic bacteria and acetogenic bacteria are able to combine $\mathrm{H}_{2}$ with $\mathrm{CO}_{2}$ to form methane and acetate respectively [13]. Bjorneklett and Jenssen have shown that subjects, who produce methane during fermentation, produce appreciably less $\mathrm{H}_{2}$ in breath in response to a standard dose of lactulose. Secondly, if $\mathrm{H}_{2}$ is not further metabolized, fermentation may be incomplete and intermediates such as lactate, succinate, and ethanol are likely to accumulate [12]. Dlactate, produced by colonic bacteria, is only partially metabolized in humans and can cause severe metabolic disturbance in certain situations. The end products of these terminal oxidative reactions differ in their toxicity. Methane is a harmless gas, readily expelled and acetate is absorbed and metabolized by peripheral tissues such as muscle, but H2S is highly toxic and may poison colonic epithelial cells if not oxidized rapidly after absorption [13].

The capacity for high rates of $\mathrm{H}_{2} \mathrm{~S}$ production exists in some people and it may be that SRB play a part in the etiology of some intestinal and extra intestinal disorders [13]. Indeed, disorders in $\mathrm{H}_{2}$ and $\mathrm{CH}_{4}$ pathways, with or without intestinal symptoms, have been also detected in several diseases, including endocrinological (thyroid, diabetes), neurological (Parkinson disease), autoimmune disorders (psoriasis), infectious diseases and iatrogenic diseases (chemotherapy or surgery) [12]. Recent studies suggest that enteric bacteria play a crucial role in $\mathrm{H}_{2}$ pathways dis metabolism. In fact $\mathrm{H}_{2}$ breath tests are more frequently altered in subjects with irritable bowel syndrome (IBS), which also display several alterations in gut microbiota composition. This concept was initially based on the common finding of an abnormal lactulose breath test, suggesting the presence of small intestinal bacterial overgrowth in IBS patients [14]. A meta analysis by Shah showed that an altered breath test is more common in IBS patients compared to control subjects and the prevalence of abnormal breath test was even more significant when examining high quality aged and sex matched studies [15]. The abnormal fermentation timing and dynamics of the breath test findings support a role for an abnormal intestinal bacterial distribution in IBS. However many bacteria in the gut utilize hydrogen gas for their energy source including methanogens and SRB. The presence of these bacteria can significantly impair the accurate detection of hydrogen [16].

\section{Pathophysiological Implications of Gastro Intestinal Gas Production}

The volume of each gas within the intestinal lumen reflects the balance between the input and output of that gas. Input may result from swallowing, chemical reactions, bacterial fermentation, and diffusion from the blood, whereas output involves belching, bacterial consumption, absorption into the blood, and anal evacuation [17]. Measurements of intestinal gas volume originally obtained using a body plethysmograph and later using a washout technique, indicated that the volume of intestinal gas in healthy subjects is approximately $200 \mathrm{~mL}$ [9]. Similar data have been reported using a specifically designed and validated computed tomography (CT) technique [8]. In the fasting state, the healthy gastrointestinal tract contains about $100 \mathrm{~mL}$ of gas, distributed almost equally among six compartments: stomach, small intestine, ascending colon, transverse colon, descending colon, and distal (pelvic) colon. Postprandially, the volume of gas increases by $65 \%$, primarily in the pelvic colon [17] and enters the stomach primarily via air swallowing and a sizable fraction is eructated. Some oxygen in swallowed air diffuses into the gastric mucosa.

The reaction of acid and bicarbonate in the duodenum yields copious $\mathrm{CO}_{2}$, which diffuses into the blood, while $\mathrm{N}_{2}$ diffuses into the lumen down the gradient established by $\mathrm{CO}_{2}$ production. In the colon, bacterial metabolism of fermentable substrates releases $\mathrm{CO}_{2}$, $\mathrm{H}_{2}$, and $\mathrm{CH}_{4}$, as well as a variety of trace gases. Fractions of these bacteriaderived gases are absorbed and metabolized or excreted in expired air. In addition, a large proportion of $\mathrm{H}_{2}$ is consumed by other bacteria to reduce sulfate to sulfide, $\mathrm{CO}_{2}$ to acetate, and $\mathrm{CO}_{2}$ to $\mathrm{CH}_{4}$, thereby reducing the net volume of gas derived from bacterial metabolism. $\mathrm{N}_{2}$ and $\mathrm{O}_{2}$ diffuse from the blood into the colonic lumen down a gradient created by the production of gas by bacteria. Gas ordinarily is propelled through the gastrointestinal tract and excreted per rectum [4]. The net result of these processes determines the volume and composition of intestinal gas [18].

Symptoms commonly attributed to too much gas, such as abdominal bloating and distention, are among the most frequently encountered gastrointestinal complaints. Bloating refers to subjective sensations of a swollen abdomen, full belly, abdominal pressure, or excess gas. Abdominal distention refers to an objective increase in girth. Distention usually develops following meals or at the end of the day and resolves after an overnight rest. Some IBS patients, particularly those with rectal hypersensitivity, however, complain of bloating in the absence of objective distention. A major question is to what extent subjective bloating and objective distention are associated with or caused by an increased rate of production or volume of intestinal gas [17]. The role of intestinal gas in functional abdominal pain has been studied since 1975. By using a washout technique with intestinal infusion of an inert gas mixture in 12 fasting patients with chronic complaints, the volume of gas excess did not differ significantly from that of 10 controls. Similarly there was no difference in the composition or accumulation rate of intestinal gas. However, more gas tended to 
reflux back in to stomach in patients who complained of abdominal pain [17].

Bowel habit is strictly reliant on intestinal transit time [19]. In particular three independent studies reported slower intestinal transit time in subjects with known production of methane compared to non methane producers [17]. Lactulose breath test among IBS patients is highly associated with constipation. The role of methane in slowing down the transit time was shown by Pimentel et al, using an interesting and well characterized canine model. Briefly, two chronic small intestinal fistulas were created surgically, at $10 \mathrm{~cm}$ distal to the bile and pancreatic ducts and 160 $\mathrm{cm}$ (mid gut fistula) from the pylorus. To test for the effect of gas on transit, room air or methane was delivered into the distal half of the gut. Luminal methane infusion reduced radioactive marker recovery in all dogs compared with room air by an average of $59 \%$ [19]. If it is true that methane is modifying gastrointestinal transit time it is also true, according to other reports that gastrointestinal transit time could influence methane and gas production. El Oufir et al, in fact, have investigated the relations between transit time, fermentation products and hydrogen consuming flora in healthy humans [7].

Eight healthy volunteers, four methane excretors and four non methane excretors were studied for three week periods during which they received a controlled diet alone and then the same diet with cisapride or loperamide. At the end of each period mean transit time (MTT) was estimated and $\mathrm{H}_{2}$ lactulose breath test was performed. Cisapride and loperamide induced MTT changes but did not affect the number of viable anaerobes per $g$ of faces. Cisapride administration induced a significant decrease in MTT and a significant increase in $\mathrm{H}_{2}$ excretion in breath while methane excretion was significantly reduced during cisapride administration [17]. No significant effect in $\mathrm{H}_{2}$ excretion but significant methane excretion was observed with loperamide administration. The authors concluded that MTT was inversely related to the volume of $\mathrm{H} 2$ excreted in breath test after lactulose ingestion. Methane excretion in breath was at a higher level during loperamide administration while the volume of exhaled $\mathrm{H}_{2}$ was hardly reduced [7].

\section{Methods for Measurement of Intestinal Gases}

Three methods are currently available for the measurement of intestinal gases in clinical settings:

a. in vivo by analyzing rectal air;

b. in vitro by fecal culturing and

c. ex vivo by breath analysis [4].

Breath analysis has a number of advantages as compared with others. The diffusivity of a gas across the mucosa of the gastrointestinal tract depends on its solubility in water; for a given partial pressure difference, $\mathrm{CO}_{2}$ diffuses much more rapidly than $\mathrm{H}_{2}, \mathrm{CH}_{4}, \mathrm{~N}_{2}$, and $\mathrm{O}_{2}$. The rate and direction of diffusion of each gas is a function of the diffusivity, partial pressure difference between lumen and blood, and exposure of the gas to the mucosal surface. $\mathrm{H}_{2}$ and $\mathrm{CH}_{4}$ absorbed from the bowel are not metabolized thus excreted in expired air, and breath analysis provides a simple means of assessing the volume of these gases in the gastrointestinal tract because it equals the their rate of absorption [20]. $\mathrm{H}_{2}$ excretion contained in the breath is the results of the alveolar ventilation rate and alveolar $\mathrm{H}_{2}$ concentration. Over the last few years, breath test analysis tried to interpret the finding of several gases and products not mentioned in this review, but the lack of standardized systems of sampling made difficult to interpret the results.

$\mathrm{H}_{2}, \mathrm{CO}_{2}$ and $\mathrm{CH}_{4}$ measurement, on the contrary, are commonly measured through relatively well standardized procedure and technical instrumentation. The correct measurement of these gases, however, needs to consider pulmonary physiology and in particular the assumption that blood concentration, which is in equilibrium with intestinal concentration of the gases, is in equilibrium with alveolar concentration of gases. Exhaled air is a mixture of alveolar air and ambient air retained in the respiratory dead space. Alveolar air is a part of exhaled air, which has been in contact with blood inside alveoli. Dead space is the volume of air which is inhaled that does not take part in the gas exchange, either because it remains in the conducting airways (anatomical dead space) and it reaches alveoli that are not perfused or poorly perfused (physiological dead space) [7]. This volume is equal to approximately $2 \mathrm{~mL} / \mathrm{kg}$ of body weight and with a normal volume of about $500 \mathrm{~mL} / \mathrm{breath}$; the first one third volume is represented by dead space air. Because of the laminar pattern of air flow through the major airways, roughly twice that volume should be exhaled before all of the dead space air is washed out. The problem is even greater with neonates, in whom dead space volume is represented by up to $50 \%$ of the tidal volume [9].

\section{Conclusion}

Intestinal gas is primarily produced by the inhabiting bacteria organisms, aerophagia and other gastrointestinal diseases associated with gas production. Nitrogen, hydrogen, methane, Oxygen and carbon di oxide are important gases within the gut lumen. Diet, specie, genetics and individual idiosyncrasies are chief factors that determine the extent of intestinal gases produced by different individuals. A better understanding of the pathophysiology of intestinal gases is essential for the improvement of current strategies employed in the decreasing the quantity of intestinal gases and in treatment of the different diseases associated with bloat and intestinal gas production and accumulation.

\section{References}

1. Newman A (2014) Review. Breath-analysis tests in gastroenterology. Gut 15: 308-323.

2. Bigard MA, Gaucher P, Lassalle C (2009) Fatal colonic explosion during colon oscopicpolypectomy. Gastroenterology 77: 1307-1310.

3. Monahan DW, Peluso FE, Goldner (2010) Combustible colonic gas levels during flexible sigmoidoscopy and colonoscopy. Gastrointestinal Endoscopy 38(1): 40-43.

4. Miller TI, Wolin MJ (1982) Enumeration of Methanobrevibactersmithii in human feces. Archive of Microbiology 131(1): 14-18.

5. Hickey CA, Calloway DH, Murphy EL (2002) Intestinal gas production following ingestion of fruits and fruit juices. American Journal of Digestive Diseases 17(5): 383-389. 
6. Kirk E (2014) The quantity and composition of human colonic flatus. Gastroenterology 12(5): 782-794.

7. El Oufir L, Flourie B, Bruley Des Varannes S, Barry JL, Cloarec D, et al. (2013) Relations betweentransit time, fermentation products, and hydrogenconsuming flora in healthy humans Gut 38(6): 870-877.

8. Mc Williams SR, Mc Laughlin PD, Oconnor OJ, Desmond AN, NíLaoíre A, et al. (2012) Computed tomography assessment of intestinal gas volumes in functional gastro intestinal disorders. Journal of Neurogastroenterology Motility 18(4): 419-425.

9. Azpiroz F, Levitt MD (2010) Intestinal Gas. Sleisenger and Fordtran's Gastrointestinal and Liver Disease ( $9^{\text {th }}$ edn.). Saunders, Elsevier, Philadelphia, USA.

10. Sahota SS, Bramley PM, Menzies IS (2012) The fermentation of lactulose by colonic bacteria. Journal of General Microbiology 128(2): 319-325

11. Gibson GR, Cummings JH, Macfarlane GT, Allison C, Segal I, et al. (1990) Alternative pathways for hydrogen disposal during fermentation in the human colon. Gut 31(6): 679-683.

12. Bjorneklett A, Jenssen E (2014) Relationships between hydrogen $\left(\mathrm{H}_{2}\right)$ and methane $\left(\mathrm{CH}_{4}\right)$ production in man. Scandinavian Journal of Gastroenterology 17(8): 985-992.

13. Mckay LF, Eastwood MA, Brydon WG (2015) Methane excretion in man-a study of breath, flatus, and faeces. Gastroenterology 26: 69-74.

14. Youn YH, Park JS, Jahng JH, Lim HC, Kim JH, et al. (2011) Relationships among the lactulose breath test, intestinal gas volume, and gastrointestinal symptoms in patients with irritable bowel syndrome. Digestive Disease Science 56(7): 2059-2066.
15. Shah ED, Basseri RJ, Chong K, Pimentel M (2010) Abnormal breath testing in IBS: a meta-analysis. Digestive Disease Science 55: 2441-2449.

16. Levit MD, Furne J, Springfield J, Suarez F, Demaster E (2009) Detoxification of hydrogen sulfide and methanethiol in the cecal mucosa. Journal of Clinical Investigation 104: 1107-1114.

17. Perez F, Accarino A, Azpiroz F, Quiroga S, Malagelada JR (2007) Gas distribution within the human gut: effect of meals. American Journal Gastroenterology 102(4): 842-849.

18. Jones MP (2005) Bloating and intestinal gas. Current Treatment Options Gastroenterology 8(4): 311-318.

19. Jahng J, Jung IS, Choi EJ, Conklin J, Park H (2012) The effects of methane and hydrogen gases produced by enteric bacteria on ileal motility and colonic transit time. Neurogastroenterology Motility 24: 185-190.

20. Mckay LF, Holbrook WP, Eastwood MA (2014) Methane and hydrogen production by human intestinal anaerobic bacteria. Acta Pathol Microbiol Immunol Scand B 90: 257-260.

21. Di Stefano M, Certo M, Colecchia A, Sorges M, Perri F (2009) $\mathrm{H}_{2}-$ breath tests: methodological audits inadults and children. Ailment Pharmacology 29(Suppl 1): 1-49.

22. Scaldaferri F, Nardone O, Lopetuso LR, V Petito, Bibbò S, et al. (2013) Intestinal gas production andgastrointestinal symptoms:from pathogenesis to clinical implication. European Review for Medical and Pharmacological Sciences 17(Supplement 2): 2-10.

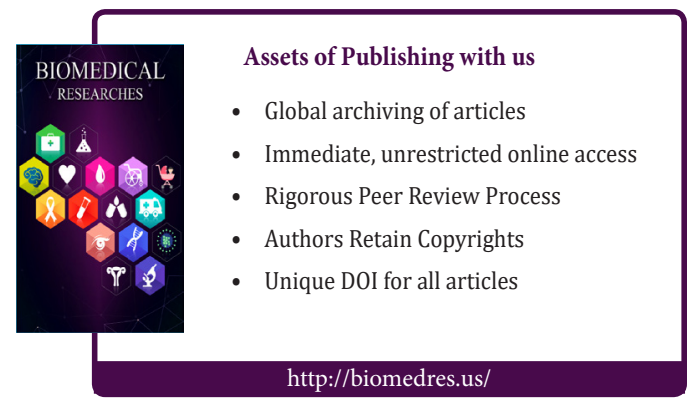

